\title{
Reactive Oxygen Species-induced Release of Signalling Factors in Irradiated Cells Triggers Membrane Signalling and Calcium Influx in Bystander Cells.
}

\author{
Fiona Lyng \\ Technological University Dublin, fiona.lyng@tudublin.ie \\ Orla L. Howe \\ Technological University Dublin, orla.howe@tudublin.ie \\ Brendan McClean \\ St Luke's Hospital
}

Follow this and additional works at: https://arrow.tudublin.ie/radart

Part of the Medicine and Health Sciences Commons

\section{Recommended Citation}

Lyng FM, Howe OL, McClean B. Reactive oxygen species-induced release of signalling factors in irradiated cells triggers membrane signalling and calcium influx in bystander cells. Int $\mathrm{J}$ Radiat Biol.

2011;87(7):683-95. doi:10.3109/09553002.2010.549533

This Article is brought to you for free and open access by the Radiation and Environmental Science Centre at ARROW@TU Dublin. It has been accepted for inclusion in Articles by an authorized administrator of ARROW@TU

Dublin. For more information, please contact

arrow.admin@tudublin.ie, aisling.coyne@tudublin.ie, gerard.connolly@tudublin.ie.

Funder: EU FP6 NOTE 
Reactive oxygen species induced release of signalling factors in irradiated cells triggers membrane signalling and calcium influx in bystander cells

Lyng F.M. ${ }^{1^{*}}$, Howe O. ${ }^{1}$, McClean B. ${ }^{2}$

${ }^{1}$ Radiation and Environmental Science Centre, Focas Research Institute, Dublin Institute of Technology, Kevin St, Dublin 8, IRELAND

${ }^{2}$ St Luke's Hospital, Highfield Road, Rathgar, Dublin 6, IRELAND

Running title: Signalling in cells exposed to medium from irradiated cells Keywords: bystander effects, signalling factors, reactive oxygen species, nitric oxide, calcium, membrane signalling

*Person to whom all correspondence should be sent:

Dr Fiona M Lyng

DIT Centre for Radiation and Environmental Science

Focas Research Institute

Dublin Institute of Technology

Kevin St, Dublin 8, IRELAND

Tel: $\quad$ ++ 35314027972

Fax: ++ 35314027904

Email: fiona.lyng@dit.ie 


\section{Abstract}

Purpose: The aim of this study was to elucidate the sequence of very early bystander signalling events and to determine the role of the different signaling molecules in both the production of the bystander signal and the response to this signal.

Materials and Methods: Human keratinocytes (HaCaT cell line) were irradiated $(0.005,0.05$ and 0.5 Gy) using a cobalt 60 teletherapy unit, the medium was harvested one hour post irradiation and transferred to recipient $\mathrm{HaCaT}$ cells. Membrane permeability and levels of calcium, reactive oxygen species and nitric oxide were measured in the recipient cells immediately after the addition of irradiated cell conditioned medium (ICCM). Inhibitors of reactive oxygen species (ROS), nitric oxide (NO), calcium and membrane signalling were used in both donor and recipient cells to investigate if bystander effects could be blocked.

Results: It was found that membrane signalling followed by calcium influx was the first response in the recipient cells to addition of ICCM. ROS, NO and calcium were all found to be important signalling molecules involved in bystander responses, while ROS and calcium were found to be involved in the production of the bystander signal.

Conclusions: The data suggest that calcium and/or ROS induce irradiated cells to release long lived signalling factors which can trigger membrane signalling and an influx of calcium further inducing ROS in unirradiated cells. 


\section{Introduction}

Radiation-induced bystander effects are characterised by the induction of biological effects in unirradiated cells as a result of receiving signals from irradiated cells (Prise \& O'Sullivan 2009, Little 2006; Mothersill \& Seymour 2006; Wright \& Coates 2006; Hamada et al. 2007; Hei et al. 2008). These effects include mutations (Nagasawa \& Little 1999; Zhou et al. 2000), transformation (Sawant et al. 2001), cytogenetic damage (sister chromatid exchanges, chromosomal aberrations, micronucleus formation) (Nagasawa 1992; Prise 1998; Sawant et al. 2001), changes in gene expression (Nagasawa 1992; Azzam et al. 1998; Prise 1998; Sawant et al. 2001; Klokov et al. 2004; Ghandhi et al. 2008), proliferation (lyer et al. 2000; Belyakov et al. 2003), and cell death (Mothersill \& Seymour 1997; Mothersill \& Seymour 1998). Protective responses like apoptosis (Belyakov et al. 1999; Lyng et al. 2000, 2002; Lyng et al. 2006), terminal differentiation (Belyakov et al. 2002, 2006; Vines et al. 2009) and radioadaptive responses (Belyakov et al. 2002; lyer \& Lehnert 2002; Mitchell et al. 2004; Belyakov et al. 2006; Maguire et al. 2007; Vines et al. 2009) have also been described.

Although these bystander effects have been well documented over the past decade, the underlying mechanisms are still unclear. Whether through direct cell to cell communication by gap junctions or secretion of soluble factors into the cell culture medium, it is likely that several different pathways are involved. 
Bystander effects have been shown to be mediated by a variety of signalling factors including reactive oxygen species (ROS) (Lehnert et al. 1997; Wu et al. 1999; Azzam et al. 2002; Lyng et al. 2006; Harada et al. 2008), nitric oxide (NO) (Matsumoto et al. 2001; Shao et al. 2002; Harada et al. 2008), second messengers like calcium (Lyng et al. 2000, 2002; Lyng et al. 2006; Shao et al. 2006), cytokines such as transforming growth factor beta (TGF $\beta$ ) (lyer et al. 2000; Shao et al. 2008) and interleukins (Osterreicher et al. 2003; Facoetti et al. 2006; Facoetti et al. 2009) and tumour necrosis factor alpha (TNF- $\alpha$ ) and tumor necrosis (TNF)-related apoptosis-inducing ligand (TRAIL) death inducing pathways (Shareef et al. 2007; Luce et al. 2009). In addition, cyclooxygenase-2 (COX-2) (Zhou et al. 2005; Hei et al. 2008), Nuclear Factor KappaB (NFkB) (Azzam et al. 2002; Zhou et al. 2008) and mitogen-activated protein (MAP) kinase (Azzam et al. 2002; Zhou et al. 2005; Lyng et al. 2006) signalling have all been shown to be involved in bystander responses. Membrane signalling has also been shown to play an important role in bystander responses (Nagasawa et al. 2002; Shao et al. 2004; Burdak-Rothkamm et al. 2007; Tartier et al. 2007).

Our previous work has shown signalling pathways in bystander cells leading to apoptosis, such as calcium, MAP kinase, mitochondrial and ROS signalling (Lyng et al. 2000, 2002; Lyng et al. 2006). The aim of this study was to follow calcium, reactive oxygen and nitrogen species and membrane signaling singly and simultaneously to elucidate the sequence of very early signalling events in the 
bystander cells. A further aim was to determine the role of the signaling molecules in both the production of the bystander signal and the response to this signal. 


\section{Materials and Methods}

\section{Cell Culture}

A human keratinocyte cell line, HaCaT cells, originally obtained as a kind gift from Dr. Petra Boukamp, Deutsches Krebsforschungszentrum (DKFZ), Germany, was used for this study. These cells are immortal but non-malignant with a doubling time of 21 hours (Boukamp 1988) with a deletion in one allele of tumour protein 53 (p53) and a point mutation in the other (Lehman 1993). HaCaT cells were cultured in Dulbecco's Modified Eagle Medium (DMEM): Nutrient Mixture F12 Ham (F12) (1:1) medium (Sigma, Dorset, U.K) containing, 10\% fetal bovine serum (Gibco, Irvine, U.K.) 1\% penicillin-streptomycin solution 1000 IU (Gibco) and $1 \mu \mathrm{g} / \mathrm{ml}$ hydrocortisone (Sigma). Cells were maintained in an incubator at $37^{\circ} \mathrm{C}$, with $95 \%$ humidity and $5 \% \mathrm{CO}_{2}$. Subculture was routinely performed when cells were $70-80 \%$ confluent, using a $1: 1$ solution of $0.2 \%$ trypsin (Sigma) and $1 \mathrm{mM}$ versene (Sigma) at $37^{\circ} \mathrm{C}$.

\section{Irradiation}

Culture flasks $\left(25 \mathrm{~cm}^{2}, 40 \mathrm{ml}\right.$ flasks, Nunc, Roskilde, Denmark) containing approx $2 \times 10^{5}$ cells were irradiated at room temperature using a cobalt 60 teletherapy unit delivering approximately $1.5 \mathrm{~Gy} / \mathrm{min}$ during the time period of these experiments. The source to sample distance was 80 centimetres and the field size was $30 \times 30$ centimetres. For the $0.005 \mathrm{~Gy}$ dose, an extended source to flask distance of $170 \mathrm{~cm}$ was used. Thermoluminescent dosimeters (TLD) were 
used to confirm that the appropriate dose was delivered. Control flasks were sham irradiated. Cells were returned to the incubator immediately after irradiation. A further set of controls included irradiated medium (with no cells) to exclude effects of medium constituents. There was no significant difference between the sham irradiated controls and the irradiated medium controls.

\section{Generation of Irradiated Cell Conditioned Medium (ICCM)}

Medium from irradiated and unirradiated cells was poured off donor flasks one hour after irradiation and filtered through a $0.22 \mu \mathrm{m}$ filter (Nalgene/Thermo Fisher, Hereford, United Kingdom) to ensure that no cells could still be present in the transferred medium (Mothersill \& Seymour 1997). The medium was then aliquoted, stored at $-80^{\circ} \mathrm{C}$ and thawed only once when required for experiments. Recipient cells were plated at a density of approx $2 \times 10^{5}$ cells per $35 \mathrm{~mm}$ glass bottomed Petri dish (Mat Tek Corp, Ashland, MA, USA) for live cell imaging, and exposed to ICCM as detailed below.

\section{Cell viability assay}

Cells were seeded in 96-well microplates (Sarstedt, Wexford, Ireland) at a density of $1 \times 10^{4}$ cells per well. This density was found to be optimal to achieve the desired confluence at the end of the exposure period. After $24 \mathrm{~h}$ of cell attachment, plates were washed with $100 \mu \mathrm{l} /$ well phosphate buffered saline (PBS) and cells treated with ICCM for $24 \mathrm{~h}$. Six replicate wells were used for 0Gy, 0.005Gy, 0.05Gy and 0.5Gy ICCM per microplate. Viability was assessed 
using the Alamar Blue assay. Following $24 \mathrm{~h}$ of exposure, ICCM was removed, cells rinsed with PBS and were incubated with 5\% Alamar Blue (Invitrogen, BioSciences, Dublin, Ireland) in DMEM:F12 without phenol red (Sigma) for 3 hours and fluorescence was read at an excitation wavelength of $485 \mathrm{~nm}$ and an emission wavelength of $545 \mathrm{~nm}$ using a Tecan Genios microplate reader. Clonogenic assays could not be carried out to assess survival because no colonies formed in the flasks incubated with the different inhibitors for 7 days. No significant toxic effects were found after 24 hour incubation so the Alamar Blue assay was used as an alternative means to assess cell viability.

\section{Live cell imaging}

Intracellular calcium levels were determined relative to control levels using Fluo 3 and Fura Red (Invitrogen / Molecular Probes, BioSciences, Dublin, Ireland) as previously described (Lyng et al. 2006). Briefly, cells were washed twice with a buffer containing $130 \mathrm{mM} \mathrm{NaCl}, 5 \mathrm{mM} \mathrm{KCl}, 1 \mathrm{mM} \mathrm{Na} 2 \mathrm{HPO}_{4}, 1 \mathrm{mM} \mathrm{CaCl}{ }_{2}$ and 1 $\mathrm{mM} \mathrm{MgCl} 2(\mathrm{pH} 7.4)$ and incubated with $3 \mu \mathrm{M}$ Fluo 3 and $3 \mu \mathrm{M}$ Fura Red acetoxymethyl esters for 1 hour in the buffer at $37{ }^{\circ} \mathrm{C}$. Subsequently, the cultures were washed three times with buffer. Fluo 3 and Fura Red were excited at $488 \mathrm{~nm}$ and fluorescence emissions at $525 \mathrm{~nm}$ and $660 \mathrm{~nm}$ were recorded simultaneously using a Zeiss LSM 510 confocal microscope. Images and time series data of the Fluo 3 and Fura Red fluorescence intensities were recorded every 2 seconds. Although the ratio Fluo 3 / Fura Red is normally presented as an indicator of calcium levels, the fluorescence intensities of each dye are shown 
here together with the fluorescence intensities of the other dyes used. Fluo 3 exhibits an increase in green fluorescence when bound to calcium and Fura Red exhibits a decrease in red fluorescence when bound to calcium (Lyng et al. 2006).

ROS and NO were followed in real time using the fluorescent probes 5-(and 6)chloromethyl-2',7'-dichlorodihydrofluorescein diacetate, acetyl ester (CM$\mathrm{H}_{2} \mathrm{DCFDA}$ ) (Invitrogen / Molecular Probes) and 4-amino-5-methylamino-2',7'difluorofluorescein diacetate (DAF-FM) (Invitrogen / Molecular Probes) respectively. Cultures were washed twice with a buffer containing $130 \mathrm{mM} \mathrm{NaCl}$, $5 \mathrm{mM} \mathrm{KCl}, 1 \mathrm{mM} \mathrm{Na} \mathrm{HPO}_{4}, 1 \mathrm{mM} \mathrm{CaCl}, 1 \mathrm{mM} \mathrm{MgCl} 2$ and $25 \mathrm{mM} \mathrm{4-(2-}$ hydroxyethyl)-1-piperazineethanesulfonic acid (HEPES) (pH 7.4). Cells were loaded with $5 \mu \mathrm{M}$ dye for $30 \mathrm{~min}$ in the buffer at $37{ }^{\circ} \mathrm{C}$. Subsequently, the cultures were washed three times with buffer and incubated for an additional 15 min to allow complete de-esterification of the intracellular diacetates. Membrane signaling was followed in real time using the fluorescent probe $\mathrm{N}$-(3triethylammonium)propyl)-4-(4-(dibutylamino)styryl) pyridinium dibromide (FM 143) (Invitrogen / Molecular Probes). Cultures were washed twice with Hanks Balanced Salt Solution (HBSS) (Sigma) and cells were loaded with $5 \mu \mathrm{g} / \mathrm{ml}$ dye for $1 \mathrm{~min}$ in the buffer at room temperature. Subsequently, the cultures were washed three times with HBSS and imaged immediately. The fluorescent dyes were excited at $488 \mathrm{~nm}$ and fluorescence emission at $525 \mathrm{~nm}$ (for $\mathrm{CM}-\mathrm{H}_{2}$ DCFDA and DAF-FM) and at $595 \mathrm{~nm}$ (for FM 1-43) was recorded using a Zeiss LSM 510 META confocal laser scanning microscope (Carl Zeiss, Welwyn Garden City, 
UK). Fluorescence images and time series data of the fluorescence intensities were recorded every 2 seconds. ICCM was added after 60 seconds when a stable baseline had been established. All measurements were performed at room temperature.

In some experiments, Fluo 3, Fura Red, $\mathrm{CM}-\mathrm{H}_{2}$ DCFDA and FM 1-43 were measured simultaneously in HaCaT cells. Reference spectra of each dye were first recorded in the HaCaT cells by recording lambda image stacks from 500$700 \mathrm{~nm}$ in $10 \mathrm{~nm}$ steps. The dyes were then loaded simultaneously into $\mathrm{HaCaT}$ cells and image stacks were recorded in the same wavelength range. Linear unmixing was performed using the Zeiss META software to produce time series data for each dye.

Inhibitors of ROS, NO, membrane signaling and calcium

To inhibit ROS, cultures were exposed to ICCM in the presence or absence of superoxide dismutase (SOD) (Sigma) at a final concentration of $100 \mu \mathrm{g} / \mathrm{ml}$ and catalase (Sigma) at a final concentration of $20 \mu \mathrm{g} / \mathrm{ml}$. To inhibit NO, cultures were exposed to 2-(4-carboxyphenyl)-4,4,5,5-tetramethyl-imidazoline-1-oxyl-3-oxide (c-PTIO) (Sigma) at a final concentration of $20 \mu \mathrm{M}$. Cultures were exposed to ICCM in the presence or absence of filipin (Sigma) at a final concentration of $0.5 \mu \mathrm{g} / \mathrm{ml}$ to inhibit membrane signalling.

Cultures were exposed to ICCM in the presence or absence of ethylene glycol tetraacetic acid (EGTA) (Sigma) at a final concentration of $5 \mathrm{mM}$ to chelate extracellular calcium, bis(2-aminophenoxy)ethane tetraacetic acid acetoxymethyl 
ester (BAPTA-AM) (Invitrogen / Molecular Probes) at a final concentration of $20 \mu \mathrm{M}$ to chelate intracellular calcium and verapamil (Sigma) at a final concentration of $10 \mu \mathrm{M}$ to block voltage dependent calcium channels.

Recipient cells were pre-incubated with inhibitors for 15 mins and exposed to ICCM in the presence of the inhibitor as described for live cell imaging and the cell viability assay.

Similarly, donor cells were pre-incubated with inhibitors for 15 mins and irradiated in the presence of the inhibitor. Immediately after irradiation, this medium was replaced with fresh medium. The flasks were incubated for 1 hour and ICCM was harvested as described previously.

\section{Statistical analysis}

The data are expressed as the percentage mean \pm standard error on the mean, for each of three independent experiments. Significance was assessed using the Student's t-test at $p<0.05$. 


\section{Results}

Figure 1a shows strong staining of the plasma membrane by fluorescent dye FM1-43 in HaCaT cells. The fluorescence intensity decreased rapidly (within 30 seconds) after addition of $0.5 \mathrm{~Gy}$ ICCM indicating a change in the membrane permeability (figure $1 \mathrm{a}$ and b). Similar results were observed for $0.005 \mathrm{~Gy}$ and 0.05Gy ICCM (data not shown). No change in fluorescence intensity was observed following addition of medium from unirradiated cells, 0Gy ICCM (figure 1b). The Alamar Blue cell viability assay was carried out in the presence and absence of filipin, an inhibitor of lipid rafts (figure 1c). A significant reduction in viability was observed following exposure of $\mathrm{HaCaT}$ cells to $0.05 \mathrm{~Gy}$ and $0.5 \mathrm{~Gy}$ ICCM for 24 hours. No significant reduction in viability was observed following exposure to 0.005 Gy ICCM for 24 hours. No significant toxicity was found in the cells exposed to 0Gy ICCM in the presence or absence of filipin. An increase in the viability of the cells exposed to $0.05 \mathrm{~Gy}$ and $0.5 \mathrm{~Gy}$ ICCM in the presence of filipin was observed.

Levels of ROS in HaCaT cells were measured using the fluorescent dye, CM$\mathrm{H}_{2}$ DCFDA. Figure $2 \mathrm{a}$ and $\mathrm{b}$ shows a rapid (within 30 seconds) and sustained increase in ROS levels following addition of 0.5Gy ICCM. Similar results were obtained for $0.005 \mathrm{~Gy}$ and $0.05 \mathrm{~Gy}$ ICCM (data not shown). No change in ROS levels were observed following addition of medium from unirradiated cells, 0Gy ICCM (figure 2b). Cell viability was measured in the presence and absence of 
SOD and catalase, inhibitors of ROS (figure $2 \mathrm{c}$ ). No significant toxicity was found in the cells exposed to OGy ICCM in the presence of SOD or catalase. An increase in the viability of the cells exposed to 0.05 Gy and 0.5 Gy ICCM in the presence of SOD and catalase was observed.

NO levels were measured in HaCaT cells using the fluorescent dye, DAF-FM. Figure $3 a$ and $b$ shows a steady increase in NO levels within 3 minutes of addition of $0.5 \mathrm{~Gy}$ ICCM. Similar results were obtained for $0.005 \mathrm{~Gy}$ and $0.05 \mathrm{~Gy}$ ICCM (data not shown). No change in fluorescence intensity was observed following addition of OGy ICCM (figure 3b). Cell viability was measured in the presence and absence of c-PTIO, an inhibitor of NO (figure 3c). No significant toxicity was found in the cells exposed to OGy ICCM in the presence of c-PTIO. An increase in the viability of the cells exposed to $0.05 \mathrm{~Gy}$ and $0.5 \mathrm{~Gy}$ ICCM in the presence of c-PTIO was observed.

Fluorescence intensities for Fluo 3, Fura Red, CM- $\mathrm{H}_{2}$ DCFDA and FM1-43 measured simultaneously in $\mathrm{HaCaT}$ cells are shown in Figure $4 \mathrm{a}$ and b. Following addition of $0.5 \mathrm{~Gy}$ ICCM (figure $4 \mathrm{a}$ ) or $0.005 \mathrm{~Gy}$ ICCM (figure $4 \mathrm{~b}$ ), a rapid increase in Fluo 3 fluorescence and a concomitant decrease in Fura Red fluorescence was observed indicating an increase in calcium levels. A simultaneous decrease in membrane permeability and a slightly later increase in ROS levels were also observed. Similar results were observed for 0.05 Gy ICCM 
but no changes in fluorescence intensity were observed following addition of 0Gy ICCM (data not shown).

To elucidate whether the membrane signalling observed was due to calcium signalling, Fluo 3, Fura Red and FM1-43 were loaded simultaneously in HaCaT cells and 0.5Gy ICCM was added in the presence of BAPTA-AM, a chelator of intracellular calcium. No change in fluorescence intensity of Fluo 3 or Fura Red was observed indicating no change in intracellular calcium levels (figure 4c). However, a change in membrane permeability was still observed in these HaCaT cells (figure 4c). To check that the change in membrane permeability was not due to an influx of extracellular calcium through calcium channels, a further experiment was performed where $0.5 \mathrm{~Gy}$ ICCM was added in the presence of EGTA, a chelator of extracellular calcium. As expected, no change in intracellular calcium levels was observed but again a change in membrane permeability was still observed in these HaCaT cells (data not shown). To further confirm that the change in membrane permeability was not due to opening of calcium channels, $0.5 \mathrm{~Gy}$ ICCM was added in the presence of verapamil, an inhibitor of voltage gated calcium channels. Again as expected, no change in calcium levels were observed but the change in membrane permeability was still observed in these HaCaT cells (data not shown) indicating that the membrane signalling in bystander cells is a separate signalling event to calcium signalling. Cell viability was measured in HaCaT cells exposed to ICCM in the presence or absence of BAPTA-AM, EGTA and verapamil (figure 4d). A significant reduction in viability was observed following exposure of HaCaT cells to 0.05 Gy and 0.5 Gy ICCM for 
24 hours. No significant reduction in viability was observed following exposure to 0.005 Gy ICCM for 24 hours. No significant toxicity was found in the cells exposed to 0Gy ICCM in the presence or absence of the calcium inhibitors. An increase in the viability of the cells exposed to 0.05 Gy and $0.5 \mathrm{~Gy}$ ICCM in the presence of BAPTA-AM, EGTA and verapamil was observed. To elucidate if the calcium signalling observed was a direct result of the membrane signalling, Fluo 3, Fura Red and FM1-43 were loaded simultaneously in HaCaT cells and 0.5Gy ICCM was added in the presence of filipin, an inhibitor of membrane signalling. As expected, no change in membrane permeability was observed. No change in intracellular calcium levels was observed indicating that the increase in calcium in bystander cells results from membrane signalling (figure 4e). As seen in figure 1c, exposure to ICCM in the presence of filipin results in decreased bystander cell death.

To investigate if ROS, NO or calcium were involved in the production of the bystander signal, the irradiated (donor) cells were incubated with SOD, catalase (inhibitors of ROS), c-PTIO (inhibitor of NO) and EGTA (chelator of extracellular calcium) for 15 minutes before and during irradiation and this medium was replaced immediately after irradiation with fresh medium. The cells were incubated in the fresh medium for one hour and ICCM was harvested as described previously. Figure 5a shows the effect of inhibiting ROS in the donor cells on the bystander response. No change in fluorescence intensity of Fluo 3 or Fura Red was observed in the recipient cells indicating no change in intracellular calcium levels (figure 5a). Similarly, no change in membrane permeability was 
observed (figure 5a). Cell viability was measured using the Alamar Blue assay (figure $5 b$ ). A significant increase in the viability of the cells exposed to $0.05 G y$ and 0.5 Gy ICCM where the donor cells had been incubated with SOD and catalase was observed compared to ICCM generated under normal conditions (figure 5b).

A similar effect was observed with the extracellular calcium chelator, EGTA. No calcium influx and no change in membrane permeability was observed when the donor cells were incubated with EGTA (data not shown). A significant increase in the viability of the cells exposed to $0.05 \mathrm{~Gy}$ and $0.5 \mathrm{~Gy}$ ICCM where the donor cells had been incubated with EGTA was observed compared to ICCM generated under normal conditions (figure $5 d$ ).

Figure $5 \mathrm{c}$ shows the effect of inhibiting NO with c-PTIO in the donor cells. A calcium response (increase in Fluo 3 and decrease in Fura Red) and a change in membrane permeability was observed in the recipient cells indicating no effect of inhibiting NO in the donor cells. Cell viability was measured using the Alamar Blue assay (figure $5 \mathrm{~d}$ ). No difference in the viability of the cells was observed when the donor cells had been incubated with c-PTIO compared to ICCM generated normally (figure 5d). 


\section{Discussion}

This study has elucidated for the first time the sequence of very early signalling events in HaCaT cells exposed to ICCM. Within 30 seconds of addition of ICCM, a change in the plasma membrane permeability occurs resulting in an immediate influx of calcium into the cytosol. This induces a rapid increase in ROS levels and a subsequent increase in NO levels. All of the signalling events appear to play a role in bystander induced death as when these events were inhibited, bystander cell death was blocked. In addition, ROS and calcium, but not NO, were found to play a role in bystander signal production.

Although there have been previous studies implicating membrane signalling in bystander cells (Nagasawa et al. 2002; Shao et al. 2004; Burdak-Rothkamm et al. 2007; Tartier et al. 2007), this study has shown the first direct evidence of membrane signalling within 30 seconds of addition of ICCM using a live cell imaging approach.

While there are numerous reports of bystander responses in various cell models, there is a lack of data on the mechanisms of bystander signal production in irradiated cells. Microbeam irradiation studies have clearly shown that direct DNA damage is not required in the irradiated cell to produce a bystander response (Wu et al. 1999; Shao et al. 2004). These studies showed that cytoplasmic organelles such as mitochondria could be important targets. Studies with mitochondrial DNA depleted cells have provided direct evidence of the key role of 
mitochondria in bystander responses (Tartier et al. 2007; Chen et al. 2008; Zhou et al. 2008). The results from the present study showed that calcium and ROS play important roles in bystander signal production and support the idea of the involvement of mitochondria. Elevation of intracellular calcium in the irradiated cell can result in overload of calcium in the mitochondria leading to a transient loss of membrane potential and production of ROS. Chen et al (2008) recently reported that mitochondrial calcium uptake is involved in ROS production in irradiated cells. Due to the short half lives of these radical species, it is likely that long lived soluble factors are induced by these ROS and released into the medium. Cytokines such as interleukins and TGF $\beta$ have been shown to be involved in bystander responses (lyer et al. 2000; Osterreicher et al. 2003; Facoetti et al. 2006; Shao et al. 2008; Facoetti et al. 2009) and have been shown to be induced by ROS (lyer et al. 2000).

This study has shown that in our model system, calcium and ROS are involved in both the production of the bystander signal and in the response to this signal while NO is involved in the bystander response only. Harada et al (2008) investigated the involvement of different radical species in the bystander effect. They showed that NO was involved in bystander signal formation in the irradiated cells while hydroxyl radicals or long lived radicals were involved in the responses in the bystander cells. These differences may be due to differences in experimental design as in the present study ICCM was transferred to unirradiated 
cells 1 hour after irradiation, while in the study of Harada et al (2008), irradiated cells were co-cultured with unirradiated cells immediately after irradiation.

Rzeszowska-Wolny et al (2009) investigated transcript profiles in directly irradiated and bystander cells and observed common changes including groups of transcripts involved in different functional pathways, neuroactive ligand receptor interactions, oxidative phosphorylation, cytokine-cytokine receptor interactions. Interestingly, an upregulation of the calcium signalling pathway group was also reported, consistent with the findings of the present study.

In this study, rapid membrane and calcium signaling and induction of ROS and NO have been shown in unirradiated cells following addition of ICCM. No significant differences were observed for the different doses, 0.005, 0.05 and 0.5Gy. A full signalling response was observed in all cases. Although no significant cell death was observed following addition of 0.005 Gy ICCM in the present study, previous studies have shown a small but significant reduction of approx $10 \%$ in clonogenic survival in the HPV-G cell line following exposure to 0.005Gy ICCM (Seymour \& Mothersill 2000; Liu et al. 2006). Reductions of approx $20-30 \%$ in clonogenic survival have also been reported previously (Liu et al. 2006) for both direct and bystander treatments at the higher doses used in the present study, 0.05Gy and 0.5Gy. The human keratinocyte HPV-G cell line shows a similar bystander response to the $\mathrm{HaCaT}$ cell line used in the present study. In our previous work (Liu et al. 2006), a dose threshold for bystander effects was reported with a reduction in clonogenic survival and calcium fluxes 
observed above 3mGy. In the present study, cell viability was measured 24 hours after exposure whereas in our previous study (Liu et al. 2006), clonogenic survival was measured 10 days after exposure. It is interesting, however, that a significant reduction in cell viability was measurable in bystander cells after exposure to medium from cells irradiated at higher doses (0.05 and 0.5Gy). This may be due to a dose dependent expression of survival or death signals downstream of the early events reported here and will be investigated in a future study.

Although not shown in this study, it is likely that calcium overload in the mitochondria of the irradiated cells leading to ROS induction is involved in the production of the bystander signal(s). These signals can be sensed by the bystander cells through the plasma membrane. Cytokine and growth factor receptors on the plasma membrane can activate MAPK and other pathways and can transduce signals to the cell nucleus (Zhou et al. 2005; Zhou et al. 2008). In addition, plasma membrane bound NADPH oxidase can be activated leading to a long lasting production of intracellular ROS in the bystander cells (Narayanan et al. 1997; Azzam et al. 2002). In summary, the present study has elucidated for the first time the sequence of very early signalling events in $\mathrm{HaCaT}$ cells exposed to ICCM. A change in plasma membrane permeability results in an influx of calcium into the cytosol inducing a rapid increase in ROS levels and a subsequent increase in NO levels. Calcium and ROS were found to be involved 
in both the production of the bystander signal and in the response to this signal while NO was found to be involved in the bystander response only. 


\section{Acknowledgements}

The authors are very grateful to St Luke's Hospital, Dublin for continued access to the cobalt-60 radiotherapy source.

\section{Declaration of Interest}

The authors report no conflicts of interest. The authors acknowledge financial support from the FP6 Integrated Project, Non-targeted effects of ionising radiation (NOTE) FI6R 036465. The work was also conducted as part of the National Biophotonics and Imaging Platform of Ireland (NBIPI), funded by the

Irish Government's Programme for Research in Third Level Institutions, Cycle 4 (2007-2013). 


\section{References}

Azzam El, de Toledo SM, Gooding T, Little JB 1998. Intercellular communication is involved in the bystander regulation of gene expression in human cells exposed to very low fluences of alpha particles. Radiation Research 150: 497-504.

Azzam El, De Toledo SM, Spitz DR, Little JB 2002. Oxidative metabolism modulates signal transduction and micronucleus formation in bystander cells from alpha-particle-irradiated normal human fibroblast cultures. Cancer Research 62: 5436-5442.

Belyakov OV, Prise KM, Trott KR, Michael BD 1999. Delayed lethality, apoptosis and micronucleus formation in human fibroblasts irradiated with X-rays or alpha-particles. International Journal of Radiation Biology 75(8): 985-93.

Belyakov OV, Folkard M, Mothersill C, Prise KM, Michael BD 2002. Bystanderinduced apoptosis and premature differentiation in primary urothelial explants after charged particle microbeam irradiation. Radiation Protection Dosimetry 99: 249-251.

Belyakov OV, Folkard M, Mothersill C, Prise KM, Michael BD 2003. A proliferation-dependent bystander effect in primary porcine and human urothelial explants in response to targeted irradiation. British Journal of Cancer 88: 767-774.

Belyakov OV, Folkard M, Mothersill C, Prise KM, Michael BD 2006. Bystanderinduced differentiation: a major response to targeted irradiation of a urothelial explant model. Mutation Research 597: 43-49.

Boukamp PP, R. T.; Breitkreutz, D.; Hornung, J.; Markham, A.Fusenig, N. E. 1988. Normal keratinization in a spontaneously immortalized aneuploid human keratinocyte cell line. Journal of Cell Biology 106: 761-771.

Burdak-Rothkamm S, Short SC, Folkard M, Rothkamm K, Prise KM 2007. ATRdependent radiation-induced gamma $\mathrm{H} 2 \mathrm{AX}$ foci in bystander primary human astrocytes and glioma cells. Oncogene 26: 993-1002.

Chen S, Zhao Y, Han W, Zhao G, Zhu L, Wang J, Bao L, Jiang E, Xu A, Hei TK and others 2008. Mitochondria-dependent signalling pathway are involved in the early process of radiation-induced bystander effects. British Journal of Cancer 98: 1839-1844.

Facoetti A, Mariotti L, Ballarini F, Bertolotti A, Nano R, Pasi F, Ranza E, Ottolenghi A 2009. Experimental and theoretical analysis of cytokine release for the study of radiation-induced bystander effect. International Journal of Radiation Biology 85: 690-699.

Facoetti A, Ballarini F, Cherubini R, Gerardi S, Nano R, Ottolenghi A, Prise KM, Trott KR, Zilio C 2006. Gamma ray-induced bystander effect in tumour glioblastoma cells: a specific study on cell survival, cytokine release and cytokine receptors. Radiation Protection Dosimetry 122: 271-274.

Ghandhi SA, Yaghoubian B, Amundson SA 2008. Global gene expression analyses of bystander and alpha particle irradiated normal human lung 
fibroblasts: synchronous and differential responses. BMC Medical Genomics 1: 63 .

Hamada N, Matsumoto H, Hara T, Kobayashi Y 2007. Intercellular and intracellular signaling pathways mediating ionizing radiation-induced bystander effects. Journal of Radiation Research (Tokyo) 48: 87-95.

Harada T, Kashino G, Suzuki K, Matsuda N, Kodama S, Watanabe M 2008. Different involvement of radical species in irradiated and bystander cells. International Journal of Radiation Biology 84: 809-814.

Hei TK, Zhou H, Ivanov VN, Hong M, Lieberman HB, Brenner DJ, Amundson SA, Geard CR 2008. Mechanism of radiation-induced bystander effects: a unifying model. Journal of Pharmacy and Pharmacology 60(8): 943-50.

lyer R, Lehnert BE 2002. Alpha-particle-induced increases in the radioresistance of normal human bystander cells. Radiation Research 157: 3-7.

lyer R, Lehnert BE, Svensson R 2000. Factors underlying the cell growth-related bystander responses to alpha particles. Cancer Research 60: 1290-1298.

Klokov D, Criswell T, Leskov KS, Araki S, Mayo L, Boothman DA 2004. IRinducible clusterin gene expression: a protein with potential roles in ionizing radiation-induced adaptive responses, genomic instability, and bystander effects. Mutation Research 568: 97-110.

Lehman TAM, R.; Boukamp, P.; Stanek, J.; Bennett, W. P.; Welsh, J. A.; Metcalf, R. A.; Stampfer, M. R.; Fusenig, N.; Rogan, E. M. 1993. p53 mutations in human immortalized epithelial cell lines. Carcinogenesis 14: 833-839.

Lehnert BE, Goodwin EH, Deshpande A 1997. Extracellular factor(s) following exposure to alpha particles can cause sister chromatid exchanges in normal human cells. Cancer Research 57: 2164-2171.

Little JB 2006. Cellular radiation effects and the bystander response. Mutation Research 597: 113-118.

Liu Z, Mothersill CE, McNeill FE, Lyng FM, Byun SH, Seymour CB, Prestwich WV 2006. A dose threshold for a medium transfer bystander effect for a human skin cell line. Radiation Research 166: 19-23.

Luce A, Courtin A, Levalois C, Altmeyer-Morel S, Romeo PH, Chevillard S, Lebeau J 2009. Death receptor pathways mediate targeted and nontargeted effects of ionizing radiations in breast cancer cells. Carcinogenesis 30: 432-439.

Lyng FM, Seymour CB, Mothersill C 2000. Production of a signal by irradiated cells which leads to a response in unirradiated cells characteristic of initiation of apoptosis. British Journal of Cancer 83: 1223-1230.

Lyng FM, Seymour CB, Mothersill C 2002. Initiation of apoptosis in cells exposed to medium from the progeny of irradiated cells: a possible mechanism for bystander-induced genomic instability? Radiation Research 157: 365-370.

Lyng FM, Maguire P, McClean B, Seymour C, Mothersill C 2006. The involvement of calcium and MAP kinase signaling pathways in the production of radiation-induced bystander effects. Radiation Research 165: 400-409. 
Maguire P, Mothersill C, McClean B, Seymour C, Lyng FM 2007. Modulation of radiation responses by pre-exposure to irradiated cell conditioned medium. Radiation Research 167: 485-492.

Matsumoto H, Hayashi S, Hatashita M, Ohnishi K, Shioura H, Ohtsubo T, Kitai R, Ohnishi T, Kano E 2001. Induction of radioresistance by a nitric oxidemediated bystander effect. Radiation Research 155: 387-396.

Mitchell SA, Marino SA, Brenner DJ, Hall EJ 2004. Bystander effect and adaptive response in $\mathrm{C} 3 \mathrm{H} 10 \mathrm{~T}(1 / 2)$ cells. International Journal of Radiation Biology 80: 465-472.

Mothersill C, Seymour C 1997. Medium from irradiated human epithelial cells but not human fibroblasts reduces the clonogenic survival of unirradiated cells. International Journal of Radiation Biology 71: 421-427.

Mothersill C, Seymour CB 1998. Cell-cell contact during gamma irradiation is not required to induce a bystander effect in normal human keratinocytes: evidence for release during irradiation of a signal controlling survival into the medium. Radiation Research 149: 256-262.

Mothersill C, Seymour CB 2006. Radiation-induced bystander effects and the DNA paradigm: an "out of field" perspective. Mutation Research 597: 5-10.

Nagasawa H, Little JB 1999. Unexpected sensitivity to the induction of mutations by very low doses of alpha-particle radiation: evidence for a bystander effect. Radiation Research 152: 552-557.

Nagasawa H, Cremesti A, Kolesnick R, Fuks Z, Little JB 2002. Involvement of membrane signaling in the bystander effect in irradiated cells. Cancer Research 62: 2531-2534.

Nagasawa HaL, J. B. 1992. Induction of sister chromatid exchanges by extremely low doses of alpha-particles. Cancer Research 52: 6394-6396.

Narayanan PK, Goodwin EH, Lehnert BE 1997. Alpha particles initiate biological production of superoxide anions and hydrogen peroxide in human cells. Cancer Research 57: 3963-3971.

Osterreicher J, Skopek J, Jahns J, Hildebrandt G, Psutka J, Vilasova Z, Tanner JM, Vogt J, Butz T 2003. Beta1-integrin and IL-1alpha expression as bystander effect of medium from irradiated cells: the pilot study. Acta Histochemica 105: 223-230.

Prise KM, O'Sullivan JM 2009. Radiation-induced bystander signalling in cancer therapy. Nature Reviews Cancer 9: 351-360.

Prise KM, Belyakov, O. V., Folkard, M. and Michael, B. D. 1998. Studies of bystander effects in human fibroblasts using a charged particle microbeam. International Journal of Radiation Biology 74: 793-798.

Rzeszowska-Wolny J, Herok R, Widel M, Hancock R 2009. X-irradiation and bystander effects induce similar changes of transcript profiles in most functional pathways in human melanoma cells. DNA Repair (Amst) 8: 732738.

Sawant SG, Randers-Pehrson G, Geard CR, Brenner DJ, Hall EJ 2001. The bystander effect in radiation oncogenesis: I. Transformation in $\mathrm{C} 3 \mathrm{H}$ $10 \mathrm{~T} 1 / 2$ cells in vitro can be initiated in the unirradiated neighbors of irradiated cells. Radiation Research 155: 397-401. 
Seymour CB, Mothersill C 2000. Relative contribution of bystander and targeted cell killing to the low-dose region of the radiation dose-response curve. Radiation Research 153: 508-511.

Shao C, Folkard M, Prise KM 2008. Role of TGF-beta1 and nitric oxide in the bystander response of irradiated glioma cells. Oncogene 27(4): 434-40.

Shao C, Folkard M, Michael BD, Prise KM 2004. Targeted cytoplasmic irradiation induces bystander responses. Proceedings of the National Academy of Sciences U S A 101: 13495-13500.

Shao C, Lyng FM, Folkard M, Prise KM 2006. Calcium fluxes modulate the radiation-induced bystander responses in targeted glioma and fibroblast cells. Radiation Research 166: 479-487.

Shao C, Furusawa Y, Aoki M, Matsumoto H, Ando K 2002. Nitric oxide-mediated bystander effect induced by heavy-ions in human salivary gland tumour cells. International Journal of Radiation Biology 78: 837-844.

Shareef MM, Cui N, Burikhanov R, Gupta S, Satishkumar S, Shajahan S, Mohiuddin M, Rangnekar VM, Ahmed MM 2007. Role of tumor necrosis factor-alpha and TRAIL in high-dose radiation-induced bystander signaling in lung adenocarcinoma. Cancer Research 67: 11811-11820.

Tartier L, Gilchrist S, Burdak-Rothkamm S, Folkard M, Prise KM 2007. Cytoplasmic irradiation induces mitochondrial-dependent 53BP1 protein relocalization in irradiated and bystander cells. Cancer Research 67: 5872-5879.

Vines AM, Lyng FM, McClean B, Seymour C, Mothersill CE 2009. Bystander effect induced changes in apoptosis related proteins and terminal differentiation in in vitro murine bladder cultures. International Journal of Radiation Biology 85: 48-56.

Wright EG, Coates PJ 2006. Untargeted effects of ionizing radiation: implications for radiation pathology. Mutation Research 597: 119-132.

Wu LJ, Randers-Pehrson G, Xu A, Waldren CA, Geard CR, Yu Z, Hei TK 1999. Targeted cytoplasmic irradiation with alpha particles induces mutations in mammalian cells. Proceedings of the National Academy of Sciences USA 96: 4959-4964.

Zhou H, Ivanov VN, Lien YC, Davidson M, Hei TK 2008. Mitochondrial function and nuclear factor-kappaB-mediated signaling in radiation-induced bystander effects. Cancer Research 68: 2233-2240.

Zhou H, Randers-Pehrson G, Waldren CA, Vannais D, Hall EJ, Hei TK 2000. Induction of a bystander mutagenic effect of alpha particles in mammalian cells. Proceedings of the National Academy of Sciences USA 97: 20992104.

Zhou H, Ivanov VN, Gillespie J, Geard CR, Amundson SA, Brenner DJ, Yu Z, Lieberman HB, Hei TK 2005. Mechanism of radiation-induced bystander effect: role of the cyclooxygenase-2 signaling pathway. Proceedings of the National Academy of Sciences USA 102: 14641-14646. 


\section{Figure Legends}

Figure 1 a) Cells were stained with the fluorescent dye FM 1-43 $(5 \mu \mathrm{M}$, Molecular Probes) and monitored over a 5 minute period for changes in membrane permeability before and after addition of medium from irradiated cells (0.5Gy ICCM), bar $=10 \mu \mathrm{m}$, b) Fluorescence intensity of FM 1-43 in HaCaT cells after addition of 0 Gy ICCM and 0.5Gy ICCM. ICCM was added at the time indicated by the arrow, c) \% viability as measured by the Alamar Blue assay in cultures exposed to $0 \mathrm{~Gy}, 0.005 \mathrm{~Gy}, 0.05 \mathrm{~Gy}$ or $0.5 \mathrm{~Gy}$ ICCM in the presence of an inhibitor of membrane signalling, filipin. Data are presented as the mean \pm standard error on the mean, $n=3,{ }^{*} p<0.05$

Figure 2 a) Cells were stained with the fluorescent dye $\mathrm{CM}-\mathrm{H}_{2}-\mathrm{DCFDA}$ (5 $\mu \mathrm{M}$, Molecular Probes) and monitored over a 5 minute period for levels of reactive oxygen species before and after addition of medium from irradiated cells (0.5Gy ICCM), bar $=10 \mu \mathrm{m}$, b) Fluorescence intensity of $\mathrm{CM}-\mathrm{H}_{2}-$ DCFDA in HaCaT cells after addition of 0Gy ICCM and 0.5Gy ICCM. ICCM was added at the time indicated by the arrow, c) \% viability as measured by the Alamar Blue assay in cultures exposed to 0Gy, 0.005 Gy, 0.05 Gy or 0.5 Gy ICCM in the presence of inhibitors of reactive oxygen species, superoxide dismutase (SOD) and catalase. Data are presented as the mean \pm standard error on the mean, $n=3,{ }^{*} p<0.05$ 
Figure 3 a) Cells were stained with the fluorescent dye DAF-FM $(5 \mu \mathrm{M}$, Molecular Probes) and monitored over a 5 minute period for levels of nitric oxide before and after addition of medium from irradiated cells (0.5Gy ICCM), bar $=10$ $\mu \mathrm{m}$, b) Fluorescence intensity of DAF-FM in HaCaT cells after addition of OGy ICCM and 0.5Gy ICCM. ICCM was added at the time indicated by the arrow, C) $\%$ viability as measured by the Alamar Blue assay in cultures exposed to 0Gy, 0.005Gy, $0.05 \mathrm{~Gy}$ or $0.5 \mathrm{~Gy}$ ICCM in the presence of an NO inhibitor, c-PTIO. Data are presented as the mean \pm standard error on the mean, $n=3,{ }^{*} p<0.05$

Figure $4 \quad$ a) Cells were stained simultaneously with Fluo 3 and Fura Red (3 $\mu \mathrm{M}$, Molecular Probes), DCFDA and FM 1-43 and monitored over a 5 minute period for levels of calcium, ROS and for membrane permeability before and after addition of medium from irradiated cells (0.5Gy ICCM), b) Cells were stained simultaneously with Fluo 3 and Fura Red ( $3 \mu \mathrm{M}$, Molecular Probes), DCFDA and FM 1-43 and monitored over a 5 minute period for levels of calcium, ROS and for membrane permeability before and after addition of medium from irradiated cells (0.005Gy ICCM), c) Cells were stained simultaneously with Fluo 3, Fura Red and FM 1-43 and monitored over a 5 minute period for levels of calcium and for membrane permeability before and after addition of medium from irradiated cells (0.5Gy ICCM) in the presence of BAPTA-AM, an chelator of intracellular calcium, d) \% viability as measured by the Alamar Blue assay in cultures exposed to 0Gy, 0.005Gy, 0.05Gy or 0.5Gy ICCM in the presence of an BAPTA-AM, EGTA and verapamil, e) Cells were stained simultaneously with 
Fluo 3, Fura Red and FM 1-43 and monitored over a 5 minute period for levels of calcium and for membrane permeability before and after addition of medium from irradiated cells (0.5Gy ICCM) in the presence of filipin, an inhibitor of membrane signaling. Live cell imaging data is representative of at least 6 independent experiments. Viability data is presented as the mean \pm standard error on the mean, $n=3,{ }^{*} p<0.05$

Figure 5 a) Cells were stained simultaneously with Fluo 3, Fura Red and FM 1-43 and monitored over a 5 minute period for levels of calcium and for membrane permeability before and after addition of medium from cells irradiated in the presence of SOD (0.5Gy ICCM), b) \% viability as measured by the Alamar Blue assay in cultures exposed to medium from cells irradiated in the presence of SOD and catalase (0Gy, $0.005 \mathrm{~Gy}, 0.05 \mathrm{~Gy}$ or $0.5 \mathrm{~Gy}$ ICCM), c) Cells were stained simultaneously with Fluo 3, Fura Red and FM 1-43 and monitored over a 5 minute period for levels of calcium and for membrane permeability before and after addition of medium from cells irradiated in the presence of c-PTIO (0.5Gy ICCM), d) \% viability as measured by the Alamar Blue assay in cultures exposed to medium from cells irradiated in the presence of EGTA and c-PTIO (0Gy, 0.005Gy, 0.05 Gy or 0.5 Gy ICCM). Live cell imaging data is representative of at least 6 independent experiments. Viability data is presented as the mean \pm standard error on the mean, $n=3,{ }^{*} p<0.05$ 